\title{
Spiritual Well-Being and Correlated Factors in Subjects With Advanced COPD or Lung Cancer
}

\author{
Takaaki Hasegawa MD, Momoko Kawai RN, Nanori Kuzuya RN CNS MSN, \\ Yohei Futamura MD, Akane Horiba MD, Takashi Ishiguro MD, Tsutomu Yoshida MD PhD, \\ Toshiyuki Sawa MD PhD, and Yasuyuki Sugiyama MD PhD
}

\begin{abstract}
BACKGROUND: Spiritual care for patients with COPD has rarely been discussed, and thus much remains unknown about their needs. The aims of this study were to identify the factors associated with spiritual well-being and to compare the levels of spiritual well-being between subjects with advanced COPD and those with inoperable lung cancer. METHODS: A total of 96 subjects with COPD or lung cancer participated in this study, which was conducted between December 2014 and April 2016. Measures included the Japanese version of the 12-item Functional Assessment of Chronic Illness Therapy-Spiritual Well-Being (FACIT-Sp-12) scale, the McGill Quality of Life Questionnaire (MQOL), the modified Medical Research Council (mMRC) dyspnea scale, and various other medico-social factors. RESULTS: No significant differences were found between subjects with COPD and those with lung cancer in median FACIT-Sp-12 scores (COPD, 27; lung cancer, 26; $P=.81)$. However, significant differences were found in the 2 MQOL domains, suggesting that subjects with COPD had a better psychological state $(P=.01)$ and that subjects with lung cancer had a better support state $(P=.002)$. Multiple regression analysis revealed that $\mathrm{mMRC}$ was significantly associated with FACIT-Sp-12 scores in subjects with COPD. CONCLUSIONS: These results suggest that subjects with advanced COPD experience spiritual well-being similar to that of subjects with inoperable lung cancer. Key words: COPD; palliative care; lung cancer; spiritual well-being; quality of life; dyspnea. [Respir Care 2017;62(5):544-549. (C) 2017 Daedalus Enterprises]
\end{abstract}

\section{Introduction}

COPD is predominantly caused by smoking and patients present with chronic symptoms such as cough, sputum, dyspnea, and air flow obstruction. COPD is a leading cause of morbidity and mortality worldwide. ${ }^{1}$ Exacerba-

\footnotetext{
Drs Hasegawa, Futamura, Horiba, Ishiguro, Yoshida, and Sawa are affiliated with the Department of Respiratory Medicine and Medical Oncology; Drs Hasegawa, Kuzuya, Ishiguro, and Sugiyama are affiliated with the Palliative Care Center; and Ms Kawai and Ms Kuzuya are affiliated with the Department of Nursing, Gifu Municipal Hospital, Gifu, Japan. Dr Hasegawa is affilated with Division of Palliative Care and Psycho-oncology, Nagoya City University Hospital, Nagoya, Japan.

The authors have disclosed no conflicts of interest.
}

Correspondence: Takaaki Hasegawa MD. Division of Palliative Care and Psycho-oncology, Nagoya City University Hospital, Mizuho-cho, Mizuhoku, Nagoya, 467-8601, Japan. E-mail: takaaki_hase@bird.ocn.ne.jp.

DOI: $10.4187 /$ respcare.05282 tions are associated with reduced quality of life (QOL) and disease progression, ${ }^{2}$ but COPD is a heterogeneous disease with several clinical and physiological phenotypes, ${ }^{3,4}$ and there is no index for prediction of 1-y risk of mortality, ${ }^{5,6}$ which makes the mortality risk easy to under- or overestimate in patients with COPD. A lack of understanding of the meaning of end-of-life care is a reported barrier to advance care planning in $\operatorname{COPD},{ }^{7}$ and patients with COPD tend to be underserved by palliative care. ${ }^{8,9} \mathrm{Al}-$ though spiritual care is considered one of the most important aspects of palliative care, spiritual well-being in patients with COPD has received only limited attention. There are few data describing levels of spiritual well-being among such patients, and physicians tend to be largely unaware of care needs in relation to spiritual well-being. We hypothesized that subjects with COPD might have equally poor levels of spiritual well-being and similar palliative care needs compared with those with lung cancer. Therefore, the aims of this study were to identify significant correlates of spiritual well-being among medico-social factors and to com- 
pare the levels of spiritual well-being between subjects with advanced COPD and those with inoperable lung cancer.

\section{Methods}

\section{Participants and Procedure}

We randomly enrolled subjects with inoperable lung cancer and Global Initiative for Chronic Obstructive Lung Disease (GOLD) stage III or IV COPD who had been treated in our department. GOLD stage III COPD is defined as an $\mathrm{FEV}_{1}$ of $<50 \%$ of the predicted value, and stage IV COPD is defined as an $\mathrm{FEV}_{1}$ of $<30 \%$ of the predicted value, or $<50 \%$ of the predicted value with chronic respiratory failure. Subjects with lung cancer were included if they were currently receiving anticancer treatment, such as chemotherapy or radiotherapy. All subjects were required to meet the following criteria before inclusion: age $\geq 20 \mathrm{y}$; sufficiently healthy to complete the questionnaire; and had been informed of their cancer or COPD diagnosis. The exclusion criteria included severe mental or cognitive disorders or an inability to understand written or spoken Japanese.

\section{Ethics, Consent, and Permissions}

Before being asked to complete the questionnaires described below, all participants were provided with a detailed description of the study purpose and methods, the privacy policy, the data management procedures, and the potential disclosure of the findings. The study protocol was approved by the institutional ethics committee of Gifu Municipal Hospital. This study is registered with the University Hospital Medical Information Network in Japan (UMIN 000015783).

\section{Measures}

Spiritual well-being was measured using a 12-item selfadministered instrument, the Functional Assessment of Chronic Illness Therapy-Spiritual Well-Being (FACITSp-12) scale. ${ }^{10-12}$ The FACIT-Sp-12 measures subjects' overall spiritual well-being and includes 2 subscales: meaning/peace and faith. The total score was obtained by summing all individual items (range, 0-44, with higher scores indicating greater spiritual well-being), and the subscale scores were obtained by summing all items in each domain. The meaning/peace subscale measures sense of meaning, peace and harmony, and purpose in life (range, $0-32$ ). The faith subscale assesses the association between illness, faith, and spiritual beliefs as well as how one finds solace in one's faith (range, $0-16$ ). The Japanese version

\section{QUICK LOOK}

\section{Current knowledge}

Patients with COPD tend to be underserved by palliative care. Physicians are rarely aware of care needs in relation to spiritual well-being. Much remains unknown about the needs of such patients.

\section{What this paper contributes to our knowledge}

Subjects with advanced COPD experienced spiritual well-being similar to that of subjects with inoperable lung cancer. Multiple regression analysis revealed that dyspnea score was significantly associated with spiritual well-being in subjects with COPD, and subjects with COPD appeared to have a worse support state than those with lung cancer.

of the FACIT-Sp-12 was chosen because its validity and reliability has been confirmed. ${ }^{13}$

The McGill Quality of Life Questionnaire (MQOL) was applied to assess QOL. ${ }^{14,15}$ The MQOL is a self-report scale composed of one item measuring overall QOL and 16 items measuring QOL in the following 4 domains: physical, psychological, existential, and support. Level of support is rated on a Likert-type scale from 0 (not at all) to 10 (extremely). The Japanese version of the MQOL, similar to the FACIT-Sp-12, has also been validated. ${ }^{16}$ The subscale score of each domain was divided by the number of items in each domain to obtain the mean subscale scores.

Dyspnea was measured using the modified Medical Research Council (mMRC) dyspnea scale. ${ }^{17}$ The mMRC dyspnea scale is a subject-rated, single-item scale in which severity is rated with 5 grades $(0=$ "I only get breathless with strenuous exercise"; 1 = "I get short of breath when hurrying on the level or walking up a slight hill"; 2 = "On level ground, I walk slower than people of the same age because of breathlessness, or have to stop for breath when walking at my own pace"; 3 = "I stop for breath after walking about 100 yards or after a few minutes on the level"; 4 = "I am too breathless to leave the house or I am breathless when dressing").

\section{Demographic, Social, and Biomedical Factors}

Demographic, social, and biomedical factors, including age, sex, marital status, occupation, and clinical stage, were obtained from the subjects' medical records. Many clinical trials for elderly subjects with COPD in Japan have enrolled subjects older than $65 \mathrm{y}$ of age ${ }^{18,19}$; therefore, $65 \mathrm{y}$ was chosen as the cutoff value for age in this study. 


\section{Spiritual Well-Being in Subjects With COPD or Lung Cancer}

\section{Statistical Analysis}

To compare the 2 groups (subjects with COPD and those with lung cancer), univariate analyses were performed using a Mann-Whitney U test. To investigate the factors associated with spiritual well-being, FACIT-Sp-12 scores were entered into the model as dependent variables. First, we performed univariate analysis on the FACIT-Sp-12 and medico-psycho-social factors using a Mann-Whitney U test, followed by multiple regression analysis. A $P$ value

Table 1. Subject Characteristics

\begin{tabular}{|c|c|c|c|}
\hline Characteristics & COPD & Lung Cancer & $P$ \\
\hline \multicolumn{4}{|l|}{ Age } \\
\hline Mean \pm SD y & $74.5(6.2)$ & $66.1(10.1)$ & \\
\hline Median (range) y & $76(61-85)$ & $67(42-84)$ & \\
\hline$<65 \mathrm{y}, n(\%)$ & $7(21.2)$ & $23(36.5)$ & .12 \\
\hline$\geq 65 \mathrm{y}, n(\%)$ & $26(78.7)$ & $40(63.4)$ & \\
\hline \multicolumn{3}{|l|}{ Sex, $n(\%)$} & .02 \\
\hline Male & $28(84.8)$ & $38(60.3)$ & \\
\hline Female & $5(15.1)$ & $25(39.6)$ & \\
\hline \multicolumn{3}{|l|}{ Marital status, $n(\%)$} & .93 \\
\hline Married & $27(81.8)$ & $52(82.5)$ & \\
\hline Widowed & $2(6.0)$ & $8(12.6)$ & \\
\hline Divorced & $2(6.0)$ & $1(1.5)$ & \\
\hline Single & $2(6.0)$ & $2(3.1)$ & \\
\hline \multicolumn{3}{|l|}{ Occupation, $n(\%)$} & .44 \\
\hline Paid employed (full-time) & $5(15.1)$ & $17(26.9)$ & \\
\hline Paid employed (part-time) & $1(3.0)$ & $2(3.1)$ & \\
\hline Self-employed & $4(12.1)$ & $5(7.9)$ & \\
\hline Unemployed or retired & $23(36.3)$ & $39(61.9)$ & \\
\hline \multicolumn{3}{|l|}{ Clinical stage, $n(\%)^{*}$} & NA \\
\hline I & $0(0)$ & $0(0)$ & \\
\hline II & $0(0)$ & $2(3.1)$ & \\
\hline III & $18(54.5)$ & $17(26.9)$ & \\
\hline IV & $15(45.4)$ & $30(47.6)$ & \\
\hline Recurrence & & $14(22.2)$ & \\
\hline \multicolumn{3}{|l|}{ mMRC, $n(\%)$} & .21 \\
\hline 0 or 1 & $15(45.4)$ & $37(58.7)$ & \\
\hline$\geq 2$ & $18(54.5)$ & $26(41.2)$ & \\
\hline \multicolumn{4}{|c|}{$\begin{array}{l}\text { * Based on the Global Initiative for Chronic Obstructive Lung Disease Stage for COPD } \\
\text { patients }{ }^{1} \text { and on the Union for International Cancer Control tumor-node-metastasis } \\
\text { classifications, 7th edition }{ }^{20} \text { for lung cancer patients. } \\
\text { NA = not applicable } \\
\text { mMRC = modified Medical Research Council dyspnea scale }\end{array}$} \\
\hline
\end{tabular}

of $<.05$ was regarded as statistically significant. All statistical analyses were performed using SPSS 21.0 (IBM Corp, Armonk, New York).

\section{Results}

\section{Subject Characteristics}

Of 107 subjects approached, 96 were enrolled in the study between December 2014 and April 2016. The reasons for non-enrollment were as follows: passive refusal $(n=5)$; lack of time $(n=3)$; lack of interest $(n=1)$; being too ill $(n=1)$; and not meeting the eligibility criteria $(n=1)$. The characteristics of the subjects are summarized in Table 1. A significant difference was found between the 2 groups in sex.

\section{FACIT-Sp-12 and MQOL Scores}

FACIT-Sp-12 scores were similar in both subject groups (Table 2). The scores on 2 subscales (meaning/peace and faith) were also similar in both groups. Table 3 shows the prevalence of symptoms in the physical domain of the MQOL. Symptoms were reported by $75 \%$ of subjects with COPD and $74 \%$ of subjects with lung cancer. The mean MQOL scores are summarized in Table 4. Significant differences in the 2 MQOL domains were found between the

Table 3. Symptoms in the Physical Domain of the McGill Quality of Life Questionnaire

\begin{tabular}{lcc}
\hline \hline \multicolumn{1}{c}{ Symptoms } & COPD & Lung Cancer \\
\hline Shortness of breath & $19(57.5)$ & $7(11.1)$ \\
Pain & $2(6.0)$ & $13(20.6)$ \\
Constipation & $0(0)$ & $14(22.2)$ \\
Tiredness & $4(12.1)$ & $8(12.6)$ \\
Trouble sleeping & $1(3.0)$ & $11(17.4)$ \\
Lack of appetite & $1(3.0)$ & $11(17.4)$ \\
Weakness & $5(15.1)$ & $3(4.7)$ \\
Diarrhea & $0(0)$ & $4(6.3)$ \\
Nausea & $0(0)$ & $4(6.3)$ \\
Cough & $2(6.0)$ & $1(1.5)$
\end{tabular}

Results are $n(\%)$

Table 2. Twelve-Item Functional Assessment of Chronic Illness Therapy-Spiritual Well-Being Scores for the Subject Groups

\begin{tabular}{lccc}
\hline \hline \multicolumn{1}{c}{ Subject Group } & FACIT-Sp-12 & Meaning and Peace & Faith \\
\hline COPD $(n=33)$, median (IQR) & $27(16.0-38.0)$ & $18(10.2-25.5)$ & $8(4.0-14.0)$ \\
Lung cancer $(n=63)$, median (IQR) & $26(21.7-36.2)$ & $18(15.0-24.0)$ & $8(6.0-11.0)$ \\
$P$ & .81 & .56 & .66
\end{tabular}

FACIT-Sp-12 = 12-item Functional Assessment of Chronic Illness Therapy-Spiritual Well-Being

$\mathrm{IQR}=$ interquartile range 
Table 4. McGill Quality of Life Questionnaire Scores for the Subject Groups

\begin{tabular}{|c|c|c|c|c|c|}
\hline Subject Group & Overall & Physical & Psychological & Existential & Support \\
\hline $\operatorname{COPD}(n=33)$ & $5.0(5.0-8.0)$ & $5.0(3.8-5.8)$ & $8.0(6.0-9.5)$ & $5.8(3.3-7.1)$ & $5.5(3.5-8.0)$ \\
\hline Lung cancer $(n=63)$ & $5.0(4.0-6.7)$ & $5.3(4.0-7.1)$ & $6.0(5.0-8.6)$ & $6.5(5.0-7.8)$ & $7.5(6.5-9.0)$ \\
\hline$P$ & .13 & .34 & .01 & .07 & .002 \\
\hline
\end{tabular}

Table 5. Factors Associated With 12-Item Functional Assessment of Chronic Illness Therapy-Spiritual Well-Being in Subjects With COPD: Multiple Regression Analysis

\begin{tabular}{lcc}
\hline \hline Subject Characteristics & $\beta$ & $P$ \\
\hline Age ( $\geq 65$ y) & 0.027 & .89 \\
Sex (female) & 0.066 & .65 \\
Marital status (married) & -0.156 & .32 \\
Occupation & -0.032 & .83 \\
Clinical stage* & 0.033 & .85 \\
mMRC ( $\geq 2)$ & -0.690 & .002 \\
MQOL & 0.317 & .11
\end{tabular}

$\mathrm{r}^{2}=0.732$

* Based on the Global Initiative for Chronic Obstructive Lung Disease Stage.

$\mathrm{mMRC}=$ modified Medical Research Council dyspnea scale

MQOL $=$ McGill Quality of Life Questionnaire

Table 6. Factors Associated With 12-Item Functional Assessment of Chronic Illness Therapy-Spiritual Well-Being in Lung Cancer Subjects: Multiple Regression Analysis

\begin{tabular}{lcc}
\hline \hline Subject Characteristics & $\beta$ & $P$ \\
\hline Age ( $\geq 65$ y) & 0.015 & .95 \\
Sex (female) & 0.211 & .29 \\
Marital status (married) & -0.246 & .28 \\
Occupation & 0.125 & .57 \\
Clinical stage* & 0.172 & .40 \\
mMRC ( $\geq 2)$ & -0.040 & .85 \\
MQOL & 0.505 & .01 \\
& & \\
$\mathrm{r}^{2}=0.377$ & & \\
* Based on the Union for International Cancer Control tumor-node-metastasis classifications, \\
7th edition. ${ }^{20}$ \\
mMRC modified Medical Research Council dyspnea scale
\end{tabular}

2 groups; subjects with COPD appeared to have a better psychological state, whereas subjects with lung cancer appeared to have a better support state.

\section{Association Between Spiritual Well-Being and Medico-Psycho-Social Factors}

The correlates of FACIT-Sp-12 in multiple regression analyses are shown in Tables 5 and 6 . mMRC was significantly correlated with FACIT-Sp-12 scores in subjects with COPD, whereas multiple regression analysis revealed a significant association between FACIT-Sp-12 and MQOL scores in subjects with lung cancer.

\section{Discussion}

To the best of our knowledge, this is the first study to attempt to compare spiritual well-being in subjects with COPD with that of subjects with lung cancer in Japan. We found that subjects with advanced COPD appeared to experience spiritual well-being on a level similar to that of those with inoperable lung cancer.

Similar to pulmonologists in many countries, Japanese pulmonologists typically care for patients with COPD and lung cancer in the same hospital setting and with the same medical and nursing teams. Several studies have suggested that early palliative care is beneficial to patients with advanced cancer, ${ }^{21,22}$ and numerous hospitals in Japan promote palliative care for patients with advanced cancer. Furthermore, care in relation to spiritual well-being is very important in palliative care. ${ }^{23}$ However, despite the fact that patients with COPD might have equally poor levels of spiritual well-being and similar palliative care needs compared with those of patients with lung cancer, palliative care that includes spiritual care for subjects with COPD has received little attention in Japan.

Few studies have evaluated the importance of spiritual well-being in subjects with lung cancer receiving aggressive treatment. Furthermore, spiritual care for patients with cancer is provided mainly in specialized palliative-care settings, such as palliative-care units or the home. When a diagnosis of advanced lung cancer is made, the focus is not only on maximizing survival prospects, but also on how best to support patients through their illness. By aiming to explore spiritual well-being in subjects with advanced lung cancer receiving aggressive treatment, our study may be useful for providing better care for these patients. Although the actual scores were not directly compared with those from other studies, the FACIT-Sp-12 scores in subjects with lung cancer in this study were similar to those in previous reports involving subjects with lung cancer receiving anticancer treatment. ${ }^{13,24}$ Furthermore, compared with the FACIT-Sp-12 scores in the present study, those in a previous study involving terminally ill subjects with can- 


\section{Spiritual Well-Being in Subjects With COPD or Lung Cancer}

cer were lower. ${ }^{25}$ In general, appropriate scores among Japanese subjects with lung cancer who were receiving anticancer treatment could be measured in our study, thereby allowing a comparison with subjects with COPD.

The results suggested that spiritual well-being was correlated with mMRC score in subjects with COPD. A higher symptom burden (an mMRC score of $\geq 2$ ) could more accurately predict mortality in subjects with COPD. Patients with stage III or IV COPD with a higher symptom burden have been thought to have a poor prognosis. ${ }^{1}$ In the present study, we found that such subjects tended to have lower levels of spiritual well-being. Therefore, not only the risk of exacerbation needs to be reduced in these patients, but also their spiritual pain needs to be alleviated. These findings may contribute to an improved understanding of unmet needs for palliative interventions in these populations.

Our study measured QOL and spiritual well-being concurrently. We found that spiritual well-being was associated with QOL among subjects with lung cancer; therefore, providing spiritual care might improve QOL among such patients. Although no differences were observed between subjects with COPD and those with lung cancer in overall QOL, subjects with COPD had worse support states than subjects with lung cancer. Previous studies have reported that subjects with COPD tended to have poor support systems, $, 9,26,27$ and our results appear to align with these findings.

Our study did have several limitations. The sample size was small and from a single institution. Furthermore, FACIT-Sp-12 scores in subjects with COPD were similar to those in subjects with lung cancer, suggesting that the spiritual pain experienced in both diseases was similar. The need to provide care for spiritual pain among both patients with COPD and those with lung cancer in the clinical setting should be considered.

Therefore, a new intervention program designed to manage the spiritual well-being of patients with COPD could be beneficial. Previous studies have reported the efficacy of short-term life-review interviews and dignity therapy on the spiritual well-being of terminally ill subjects with cancer. ${ }^{25,28}$ Future research exploring the effects of these psychotherapies to enhance the spiritual well-being of patients with COPD might therefore be needed.

\section{Conclusions}

The results of this study suggest that subjects with advanced COPD experience a level of spiritual well-being similar to that of subjects with inoperable lung cancer. Therefore, clinicians should pay more attention to spiritual pain among patients with COPD and attempt to provide appropriate spiritual care. Further research is needed to explore interventions that support spiritual well-being in both subjects with COPD and those with advanced cancer.

\section{ACKNOWLEDGMENTS}

We thank all of the subjects who participated in this study. We are also grateful to Satomi Okita RN for assistance with the recruitment of participants.

\section{REFERENCES}

1. Global Initiative for Chronic Obstructive Lung Disease. Global Strategy for the Diagnosis, Management, and Prevention of Chronic Obstructive Pulmonary Disease, updated 2015. http://www.goldcopd.org. Accessed April 30, 2016.

2. Vestbo J, Hurd SS, Agustí AG, Jones PW, Vogelmeier C, Anzueto A, et al. Global strategy for diagnosis, management, and prevention of chronic obstructive pulmonary disease: GOLD executive summary. Am J Respir Crit Care Med 2013;187(4):347-365.

3. Agusti A, Calverley PM, Celli B, Coxson HO, Edwards LD, Lomas DA, et al. Characterisation of COPD heterogeneity in the ECLIPSE cohort. Respir Res 2010;11:122.

4. Han MK, Agusti A, Calverley PM, Celli BR, Criner G, Curtis JL, et al. Chronic obstructive pulmonary disease phenotypes: the future of COPD. Am J Respir Crit Care Med 2010;182(5):598-604.

5. Puhan MA, Garcia-Aymerich J, Frey M, ter Riet G, Antó JM, Agustí $\mathrm{AG}$, et al. Expansion of the prognostic assessment of patients with chronic obstructive pulmonary disease: the updated BODE index and the ADO index. Lancet 2009;374(9691):704-711.

6. Oga T, Tsukino M, Hajiro T, Ikeda A, Nishimura K. Predictive properties of different multidimensional staging systems in patients with chronic obstructive pulmonary disease. Int $\mathrm{J}$ Chron Obstruct Pulmon Dis 2011;6:521-526.

7. Gott M, Gardiner C, Small N, Payne S, Seamark D, Barnes S, et al. Barriers to advance care planning in chronic obstructive pulmonary disease. Palliat Med 2009;23(7):642-648.

8. Luddington L, Cox S, Higginson I, Livesley B. The need for palliative care for patients with non-cancer diseases: a review of the evidence. Int J Palliat Nurs 2001;7(5):221-226.

9. Gore JM, Brophy CJ, Greenstone MA. How well do we care for patients with end stage chronic obstructive pulmonary disease (COPD)? A comparison of palliative care and quality of life in COPD and lung cancer. Thorax 2000;55(12):1000-1006.

10. Cella DF, Tulsky DS, Gray G, Sarafian B, Linn E, Bonomi A, et al. The Functional Assessment of Cancer Therapy scale: development and validation of the general measure. J Clin Oncol 1993;11(3):570579.

11. Peterman AH, Fitchett G, Brady MJ, Hernandez L, Cella D. Measuring spiritual well-being in people with cancer: the functional assessment of chronic illness therapy-Spiritual Well-being Scale (FACIT-Sp). Ann Behav Med 2002;24(1):49-58.

12. Brady MJ, Peterman AH, Fitchett G, Mo M, Cella D. A case for including spirituality in quality of life measurement in oncology. Psychooncology 1999;8(5):417-428.

13. Noguchi W, Ohno T, Morita S, Aihara O, Tsujii H, Shimozuma K, Matsushima E. Reliability and validity of the Functional Assessment of Chronic Illness Therapy-Spiritual (FACIT-Sp) for Japanese patients with cancer. Support Care Cancer 2004;12(4):240-245.

14. Cohen SR, Mount BM, Strobel MG, Bui F. The McGill Quality of Life Questionnaire: a measure of quality of life appropriate for people with advanced disease: a preliminary study of validity and acceptability. Palliat Med 1995;9(3):207-219.

15. Cohen SR, Mount BM, Bruera E, Provost M, Rowe J, Tong K. Validity of the McGill Quality of Life Questionnaire in the palliative care setting. A multi-center Canadian study demonstrating the importance of the existential domain. Palliat Med 1997;11(1):3-20.

16. Tsujikawa M, Yokoyama K, Urakawa K, Onishi K. Reliability and validity of Japanese version of the McGill Quality of Life Question- 


\section{Spiritual Well-Being in Subjects With COPD or Lung Cancer}

naire assessed by application in palliative care wards. Palliat Med 2009;23(7):659-664.

17. Bestall JC, Paul EA, Garrod R, Garnham R, Jones PW, Wedzicha JA. Usefulness of the Medical Research Council (MRC) dyspnoea scale as a measure of disability in patients with chronic obstructive pulmonary disease. Thorax 1999;54(7):581-586.

18. Katsura H, Kanemaru A, Yamada K, Motegi T, Wakabayashi R, Kida K. Long-term effectiveness of an inpatient pulmonary rehabilitation program for elderly COPD patients: comparison between young-elderly and old-elderly groups Respirology 9(2):230-236, 2004.

19. Hiratsuka T, Kida K. Quality of life measurements using a linear analog scale for elderly patients with chronic lung disease. Intern Med 1993;32(11):832-836.

20. Goldstraw P, Crowley J, Chansky K, Giroux DJ, Groome PA, RamiPorta R, et al. The IASLC Lung Cancer Staging Project: proposals for the revision of the TNM stage groupings in the forthcoming (seventh) edition of the TNM Classification of malignant tumours. J Thorac Oncol 2007;2(8):706-714.

21. Temel JS, Greer JA, Muzikansky A, Gallagher ER, Admane S, Jackson VA, et al. Early palliative care for patients with metastatic nonsmall-cell lung cancer. N Engl J Med 2010;363(8):733-742.

22. Bakitas MA, Tosteson TD, Li Z, Lyons KD, Hull JG, Li Z, et al. Early versus delayed initiation of concurrent palliative oncology care: patient outcomes in the ENABLE III randomized controlled trial. J Clin Oncol 2015;33(13):1438-1445.
23. Morita T, Kawa M, Honke Y, Kohara H, Maeyama E, Kizawa Y, et al. Existential concerns of terminally ill cancer patients receiving specialized palliative care in Japan. Support Care Cancer 2004;12(2): 137-140.

24. Kawahara M, Tada H, Tokoro A, Teramukai S, Origasa H, Kubota $\mathrm{K}$, et al. Quality-of-life evaluation for advanced non-small-cell lung cancer: a comparison between vinorelbine plus gemcitabine followed by docetaxel versus paclitaxel plus carboplatin regimens in a randomized trial: Japan Multinational Trial Organization LC00-03 (BRI LC03-01). BMC Cancer 2011;11:356.

25. Ando M, Morita T, Akechi T, Okamoto T. Efficacy of short-term life-review interviews on the spiritual well-being of terminally ill cancer patients. J Pain Symptom Manage 2010;39(6):993-1002.

26. Burton AM, Sautter JM, Tulsky JA, Lindquist JH, Hays JC, Olsen MK, et al. Burden and well-being among a diverse sample of cancer, congestive heart failure, and chronic obstructive pulmonary disease caregivers. J Pain Symptom Manage 2012;44(3):410-420.

27. Goodridge D, Lawson J, Duggleby W, Marciniuk D, Rennie D, Stang M. Health care utilization of patients with chronic obstructive pulmonary disease and lung cancer in the last 12 months of life. Respir Med 2008;102(6):885-891.

28. Chochinov HM, Kristjanson LJ, Breitbart W, McClement S, Hack TF, Hassard T, Harlos M. Effect of dignity therapy on distress and end-of-life experience in terminally ill patients: a randomised controlled trial. Lancet Oncol 2011;12(8):753-762.

This article is approved for Continuing Respiratory Care Education credit. For information and to obtain your CRCE

(free to AARC members) visit

www.rcjournal.com

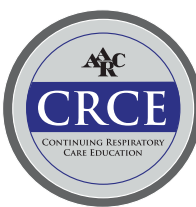

